\title{
Guangdong University of Technology Graduate Education System
}

\author{
Yi Ji \\ School of Art and Design \\ Guangdong University of Technology \\ Guangzhou, China \\ jiyi001@hotmail.com
}

\section{INTRODUCTION}

The discipline of design of at Guangdong University of Technology was founded in 1995. At present, it has established a complete talent cultivation system with bachelor's degree, master's degree and doctor's degree, and has cultivated tens of thousands of design professionals for the field of innovative design in Guangdong province.

The School of Art and Design was granted the right to confer Master's degrees in the second-level discipline of "Design and Art" in 2005, the professional degree of "Industrial Design Engineering" in 2010, the first-level discipline of "Design" in 2011, and the second-level discipline of "Industrial Design and Creative Products" in 2013.

Guangdong University of Technology School of Art and Design now has 41 master tutors, including 11 professors, 25 associate professors, 3 special professors and 3 external master tutors. It also has a group of design masters and experts and scholars from Europe, America, Japan and other countries, led by professor Hannu Kahonen, a leading industrial design master in Europe.

\section{TRAINGING OBJECTIVES}

To train high-level academic professionals to obtain master's degrees in first-level disciplines of art and design. Degree gainer should:

(i) Have a systematic design theory and system of the specialised knowledge, understand the basic history, present situation and development of this discipline to, master the design science research methods, technical means and evaluation technology, able to choose the right research direction, the reasonable use scientific method independent academic research and design practice;

(ii) $\mathrm{Be}$ able to understand the development trends of related disciplines and combine them into practice, with the ability to integrate knowledge of various disciplines and solve problems creatively;

(iii) Use a foreign language skilfully to search and consult materials, conduct academic research and communicate effectively, and lay a theoretical and methodological foundation for higher level learning and research;

(iv) Degree holders may further pursue a doctorate in a related discipline or engage in design, research or teaching in a related institution.

\section{MAIN RESEARCH DIRECTIONS}

There are five research directions under the firstlevel discipline of design:

(v) Industrial Products and Clothing Design and Their Theories;

(vi) Environmental Design and Public Art

(vii) Digital Media and Visual Communication Design

(viii) Design and Art History

(ix) Painting Creation and Theory

\section{CONTACTS}

Please contact $\mathrm{Yi} \mathrm{Ji}$ at Guangdong University of Technology School of Art and Design by email at iiiy001@hotmail.com or by telephone +86 18518152099. 